\title{
Adherence to diabetes self-care behaviors in English- and Spanish-speaking Hispanic men
}

\author{
This article was published in the following Dove Press journal: \\ Patient Preference and Adherence \\ 18 April 2009 \\ Number of times this article has been viewed
}

\author{
Luis O Rustveld' \\ Valory N Pavlik' \\ Maria L Jibaja-Weiss ${ }^{1,2}$ \\ Kimberly $\mathrm{N}$ Kline $^{3}$ \\ J Travis Gossey' \\ Robert J Volk' \\ 'Baylor College of Medicine, \\ Department of Family \\ and Community Medicine, Houston, \\ TX, USA; ${ }^{2}$ Outreach and Health \\ Disparities, Dan L. Duncan \\ Cancer Center, Houston, TX, USA; \\ ${ }^{3}$ Department of Communication, \\ University of Texas \\ at San Antonio, San Antonio, \\ TX, USA
}

\begin{abstract}
We conducted a qualitative study to elicit attitudes, attributions, and self-efficacy related to diabetes self-care in both English- and Spanish-speaking Hispanic men. Transcripts from six focus groups (three in English and three in Spanish) were reviewed by the authors to extract principal and secondary themes. Participants could describe their medication and lifestyle regimens and were aware of whether they were adherent or nonadherent to physician recommendations. Lack of skills on how to incorporate diet and regular physical activity into daily living, lack of will power, and reluctance to change culturally rooted behaviors emerged as significant barriers to diabetes self-management. Medication adherence is for some men the principal diabetes self-care behavior. Nonadherence appeared to fit two profiles: 1) intentional, and 2) nonintentional. In both instances low self-efficacy emerged as a significant influence on attainment and maintenance of diabetes self-care goals. Participants also expressed a strong sense of fatalism regarding the course of their disease, and seemed to have little motivation to attempt long-term dietary control. Educational and counseling messages should stress that a diagnosis of diabetes is not a death sentence, and full functional capacity can be maintained with good control.
\end{abstract}

Keywords: type 2 diabetes, self-care, glycemic control, adherence

\section{Introduction}

The prevalence of type 2 diabetes has reached alarming rates in the United States. In particular, Hispanic Americans bear a disproportionate burden, with almost twice as many affected compared to non-Hispanic whites. ${ }^{1}$ The overall age-adjusted prevalence of type 2 diabetes mellitus (T2DM) among Hispanics in the US aged 20 years and over is $11.8 \%$. Physician-diagnosed T2DM is higher for Hispanic men, compared to Hispanic women (6.1\% vs 5.1\%, respectively). ${ }^{2}$ When compared to other racial/ethnic groups, Hispanics have worse glycemic control, which places many at significant risk for long-term complications such as cardiovascular disease, end-stage renal disease, amputations, and visual impairment. ${ }^{3}$ In a sample of patients with type 2 diabetes followed in the public clinic system in which the present study was carried out, Hispanics had an average $\mathrm{HbA} 1 \mathrm{c}$ of $8.6 \% \pm 1.8 \%$ compared to $7.5 \% \pm 1.8 \%$ in African Americans and 7.7\% $\pm 1.3 \%$ in non-Hispanic whites. An HbA1c of less than 7 is recommended as normal by the American Diabetes Association (ADA). ${ }^{4}$

Several potential mechanisms for racial/ethnic disparities in diabetes control have been proposed, including lack of access to health care and cultural or linguistic barriers to health care information, and sociocultural or economic barriers to adherence behaviors. ${ }^{5}$ In particular, data on knowledge and attitudes of Hispanic men regarding 
diabetes self-management are lacking. Since Hispanic men in the US are least likely to have a usual source of care and to have contact with the medical system, ${ }^{6}$ this is an important group to target for interventions to improve chronic disease control. For example, the National Health Interview Surveys indicate that even when Hispanic men report being in good to excellent health, they are less likely to have visited a doctor in the past two years compared to non-Hispanic white men (34\% vs 20\%, respectively). ${ }^{7}$

Considerable emphasis has been placed on evaluating health care access barriers such as lack of insurance coverage, low income and education as major determinants of adherence. We designed the present study to provide insight into the belief systems and attitudes of Hispanic men with diabetes toward diabetes and recommended self-management behaviors. We were particularly interested in eliciting their attitudes toward the importance of adhering to all aspects of the diabetes regimen. Our approach differed in that we explored potential barriers to diabetes management guidelines in a group of Hispanic men with equal access to care.

\section{Research design and methodology Design}

This study was a descriptive qualitative study using focus groups with 34 English- and Spanish-speaking Hispanic men to determine factors related to lack of adherence to a diabetes regimen.

\section{Participants and setting}

Focus group participants were initially identified by diabetes educators at three Harris County Hospital District (HCHD) community health centers in Houston, Texas. This public health care system serves approximately 200,000 low-income patients and consists of two general hospitals, 11 community health centers, and a variety of specialty treatment facilities. Medical care in the system is provided by faculty of two medical schools. Participants had to meet the following inclusion criteria: 1) had to be a patient at one of the clinics; 2) 18 years or older; 3) have a diagnosis of type 2 diabetes; 4) English or Spanish speaker; and 5) be able to attend focus group sessions.

Participants who met eligibility criteria were identified by reviewing appointment logs and electronic medical records at the HCHD. Letters were sent to selected participants inviting them to participate in the focus group discussions, and flyers posted in clinic waiting areas. Recruitment also occurred by physician referral. This study was approved by the Institutional Review Board at Baylor College of Medicine, and the HCHD.

\section{Focus groups}

Focus groups were conducted by two experienced bilingual moderators (LR, MJW) using a semi-structured approach determined a priori. The questions were selected after a comprehensive review of the literature on diabetes care and self-management ${ }^{8-16}$ and consultation with primary care providers practicing at local community clinics (Table 1).

A total of six focus groups were conducted between April and June of 2007, with six to eight participants at each session. According to Krueger and Casey, ${ }^{17}$ three or four focus groups with a specific group of interest are sufficient to allow analysis, comparison, and contrasting of findings across groups. We were interested in exploring differences and similarities in diabetes self-management practices across two groups of men (English- and Spanish-speaking Hispanic men), therefore six focus groups were sufficient to accomplish study objectives.

At the beginning of each session, participants were asked to read and sign consent forms, and permission was obtained to audio record the sessions. Each session lasted for 90 to 120 minutes. A co-moderator was present at each focus group session. The primary responsibility of the co-moderator was to consent participants and take notes during sessions. Immediately following focus groups, the moderator and co-moderator met to review notes taken during sessions and discussed any unusual events that could influence interpretation of the data. All focus group recordings, both English and Spanish were transcribed, and Spanish recordings translated into English by professional translators. Transcripts were formatted to include English and Spanish versions of the recordings. Audio files were stored on a shared network, and transcripts were uploaded into a Nvivo ${ }^{18}$ project database, both were password protected and accessible only to authors. This database also contained moderator notes, project coding structure, and query reports.

\section{Analysis of focus group data}

Focus group transcripts and field notes were read and analyzed using qualitative data analysis techniques. ${ }^{19-22}$ Transcripts and moderator notes were read by project analysts independently and participants' responses organized into categories and codes in order to facilitate detection and interpretation of patterns emerging from the raw data. Several consensus meetings were then held with authors to discuss these emergent themes and to settle differences in interpretation of the data. 
Table I Focus group questions

\begin{tabular}{|c|c|}
\hline Main questions & Key probes \\
\hline I. How do you take care of your diabetes? & $\begin{array}{l}\text { - What medicines are you supposed to take? } \\
\text { - What diets are you supposed to follow? } \\
\text { - What type of physical activity or exercise are you supposed to do? }\end{array}$ \\
\hline 2. Do you ever decide not to take care of your diabetes? & - Do you worry about side effects? \\
\hline 3. When don't you do the things you are supposed to do? And why? & - How do you feel if you don't do the things you are supposed to do? \\
\hline 4. When do you take your medicine? & - Do you understand how to follow your diet? \\
\hline 5. How do you take your medicine? & - Do you understand how to be more physically active? \\
\hline 6. What would help you stick to your treatment plan? & $\begin{array}{l}\text { - More time with your doctor? } \\
\text { - More or different classes at the clinic? } \\
\text { - Printed information? (that is easier to understand) }\end{array}$ \\
\hline
\end{tabular}

Differences were settled by revisiting pertinent sections of transcripts and moderator notes, and in some instances audio files were also reviewed to clarify observations from the transcriptions.

We employed the framework approach described by Pope and colleagues ${ }^{21,22}$ to analyze key themes from the focus group. The framework approach provided us with a systematic process of coding pertinent textual data from focus groups transcripts at each theme. The coding and cross indexing process was facilitated by the use of Nvivo software. ${ }^{18}$

\section{Results Study sample}

A total of 34 Hispanic men (16 Spanish and 18 English speakers) with T2DM and a mean age of 54.9 years attended six focus group sessions at three HCHD community clinics. The Hispanic origin of participants reflects the typical distribution of the HCHD clinics: 80\% Mexican American, 20\% from countries other than Mexico, including El Salvador, Guatemala, and Honduras. No participants were from Puerto Rico or Cuba. A total of five men spoke English only and 13 were bilingual, but preferred to have focus group sessions conducted in English. The rest $(n=16)$ spoke primarily Spanish. The majority (90\%) were taking oral hypoglycemic agents (Table 2). A total of six men suffered from diabetes-related complications (two suffered from severe vision impairment, one had several toes amputated, another required dialysis treatment, and one suffered nerve damage in the legs).

\section{Knowledge of diabetes management recommendations}

All men seemed to be aware of the importance of diet, medication, and exercise as components of a diabetes treatment regimen $(n=34)$ :
- "Once you find out that you have diabetes, you know, you gotta completely change your lifestyle, as far as exercise, and watching what you eat."

- "When you have diabetes, you need to watch what you eat...watch your sugar intake, and take your medication."

- "If you want to keep going, you need to start eating right when it gets ya, there is no cure for it...just eating correctly and exercising..."

Despite this awareness, patients expressed a number of barriers to self-care including general barriers to self-care and those specific to diet, exercise, and medication recommendations. From these findings, profiles emerged of adherence and nonadherence.

Table 2 Characteristics of Hispanic men with type 2 diabetes $(\mathrm{N}=34)$

\begin{tabular}{ll}
\hline Characteristics & Mean, N (\%) \\
\hline Age (mean) & 57.6 \\
Language & $18(53)$ \\
English-speakers & $16(47)$ \\
Spanish-speakers & \\
Country of origin & $27(79)$ \\
Mexico & $3(9)$ \\
El Salvador & I (3) \\
Guatemala & $3(9)$ \\
Honduras & \\
Medication & $30(90)$ \\
Oral hypoglycemic agent & $2(5)$ \\
Insulin & $2(5)$ \\
Both & \\
Diabetes complications & $2(5)$ \\
Vision impairment & I (3) \\
Toe amputation & I (3) \\
Nerve damage in leg & I (3) \\
Receive dialysis treatment &
\end{tabular}




\section{General barriers to self-care}

Both English- and Spanish-speaking participants reported having some difficulty in the past comprehending diabetes management instructions given to them by their health care provider. Lack of comprehension was not necessarily the result of language barriers, but mainly difficulty applying ADA diabetes self-management guidelines into their daily routine. $^{4}$

Although most attributed stress and a general sense of frustration as main reasons why they did not adhere to treatment recommendations, depression emerged as an important topic of conversation. Men were quick to point out, however, that they themselves were not depressed, but could envision depression as the reason why people with diabetes were noncompliant. In general, Spanish-speaking men did not have any problems admitting that they felt depressed and that depression sometimes caused them to be less motivated to stick to a treatment plan. Two barriers were expressly relevant to culture: self-esteem and fatalism.

\section{Self-esteem}

Even though most men had a general understanding that adherence to their diabetes treatment plan is essential in achieving blood glucose control, they viewed their condition as a debilitating illness. Sickness is a sign of weakness, which is also viewed as a lack of masculinity, because sickness hampers their ability to fulfill the role of family provider $(\mathrm{n}=24)$ :

- "We go on suffering because maybe we can't move anymore, and then we might be a burden to our families who will have to take care of us."

An added blow to male self-esteem is the perception that they were no longer the same or that they were treated differently by their friends or employer because they have diabetes. These perceptions affected the way in which some men were able to engage in self-care behaviors $(n=21)$ :

- "When you have diabetes, you stop seeing your friends on a regular basis. You're not as happy as they are and you don't share with them the parties you shared in the past. There are times that you feel inferior to them."

- "Because of diabetes, you get less productive in your job, you get tired sooner, and that affects you because your boss doesn't want an employee like that and the boss says: bye-bye to you"

\section{Fatalism}

A more fatalistic stance was also observed in that men saw no reason to continue adhering to a treatment plan, when in the long run it won't matter anyway. The perception was that they were doomed to suffer complications $(\mathrm{n}=18)$ :

- "No matter how much you take care of yourself, that's gonna happen (referring to loss of eyesight, foot problems). I was told it's still gonna happen."

- "I told my daughter, I have to die of something, let me at least die in peace."

It is not entirely clear from the focus group findings the extent to which some men persevered before adopting a fatalistic mindset, or whether lack of diabetes control is attributed to experience with an ineffectual treatment plan, or lack of adherence altogether.

\section{Diet barriers}

Men often found it difficult to follow diet recommendations because they had difficulty translating ADA diet recommendations ${ }^{4}$ into everyday practice.

\section{Lack of knowledge about portion sizes}

Those who did try to follow a healthy diet plan found it challenging to apply portion size guidelines at every meal $(\mathrm{n}=30)$ :

- "I wish I had a better understanding of a diet. Even though I'm a cook that doesn't mean that I'm a nutritionist."

- "I can't follow the diet, I just can't. I don't know what to do to follow it, how should I go about it?"

\section{Difficulty eating less}

First, feeling full after every meal was an important expectation $(n=20)$ :

- "If there's just a little bit of food on the plate, I don't get full. I have to have at least a full plate to get full."

- "The dietitian gave me a list of stuff I could eat and couldn't eat, but I don't follow that diet, because it's nothing I could even get full on. Much less live on."

Second, some men resented having to follow a diet, because they felt deprived $(n=22)$ :

- "I feel mad, not everything you like is included in the diet. You want to make me mad? Serve me some fish or chicken."

- "You know I don't really think about it, I try not to think about it because it really makes me angry."

Third, some men found it difficult to eat several small meals throughout the day $(\mathrm{n}=19)$ :

- "I usually eat my portions every four hours, sometimes I go without, over four hours and you know, I don't realize what time it is and that's when it hits me, I start getting a little bit dizzy, start sweating." 
When at work, they would go without eating anything for four hours or more, which often resulted in low blood sugar episodes. Many men worked jobs that were physically demanding and had work schedules with set lunch breaks. Some did not make the effort to take short breaks throughout the day to eat something as recommended because they did not want to attract attention to their condition. As noted above, the perception was that their employer might find them unfit to do the job. They would then try to compensate by eating anything available to feel better. Therefore, many ate large meals once or twice a day instead of frequent small meals throughout the day.

Exacerbating this barrier, some men were under the impression that they could make up for overeating or eating foods not allowed in their diet plan by taking medication immediately following a binge, or by exercising more. This was particularly the case for those who believed medication was the principal means of taking care of their diabetes.

The men in these focus groups also revealed cultural barriers to adhering to dietary recommendations.

\section{Reluctance to alter lifestyle}

The predominant reason for not following dietary recommendation was simply that men did not want to give up their favorite foods, many of which were traditional Hispanic foods $(n=29)$ :

- "What they tell you to eat and, no, no, no, I like my tortillas, I like my bread, I like my hamburgers, I like my doughnuts, I like my fried chicken..."

- "I have to have my plate of menudo in the morning, I love that poison."

- "I don't diet, I love foods too much. I like my beer, and there's no way anybody is going to tell me I can't have any."

- "Although I'm told not to eat so many tamales because they are bad for my health, I eat them anyway and I don't worry about the consequences."

- "I just can't eat the food on the diet. I don't like it, it doesn't rock my boat. No, no, I don't like it at all. So, I do everything else, except that."

- "I know that too much food is bad for my health, but I eat a lot anyway."

Men were reluctant to try different foods, or foods prepared in a manner other than what they were used to. The perception was that even the slightest modification in food preparation would render the food tasteless and unacceptable. Furthermore, most could not imagine that Hispanic foods can be healthy if prepared in a healthy manner.
For these men, current dietary habit was greatly influenced by what they grew up eating $(\mathrm{n}=29)$ :

- "Like us Hispanics it's hard for us to eat foods that do not contain much fat or grease, because everything we grew up with was cooking that way."

\section{Importance of social traditions}

Even those men who were successful in adhering to diabetes treatment guidelines throughout the year found it difficult to stick to their regimen on weekends, holidays, special occasions, and when traveling abroad $(\mathrm{n}=22)$ :

- "I have three children and they all come to my house on Sundays, my daughter and my two sons. And we usually get out of control."

- "It's really hard, for example if you go to a get-together or party. It's hard not to participate, although you know it can be harmful. So you eat a little bit of this, a little bit of that, and there's where your willpower to keep on your diet completely disappears."

Others made no attempts to adhere to their diabetes regimen during these special occasions $(\mathrm{n}=11)$ :

- "Today I'm not a diabetic."

Nonadherence when visiting family abroad was in most cases inevitable. Family gatherings were viewed as important, and not partaking of foods and drinks was just not done. Men dealt with the consequences later $(\mathrm{n}=18)$ :

- "If there's been a long time since you last went to visit your home country and your family is there, waiting for you with lots and lots of pork and all that...it's really difficult to look at the pork and not eat it. And they'll tell you: Come on, now that you live in the US you're more used to hamburgers? You don't want to share a meal with us?"

\section{Exercise barriers}

Men were aware that exercise is an important component of their diabetes treatment plan, but most did not engage in regular physical activity $(n=20)$ :

- "I know I should avoid products that contain sugar, and I also know I should exercise, but to tell you the truth, I don't do any exercise at all."

Many of the men in these focus groups did not engage in regular exercise because of physical limitations that greatly hampered their ability to engage in sustained physical activity. Some men were no longer able to exercise at the same intensity and duration as they used to because of diabetes-related complications such as problems with vision, nerve damage in legs, amputated toes, and having to undergo dialysis treatment. 
For those men that did not suffer from physical limitations, the primary reason given for nonadherence to exercise recommendations was the belief that strenuous activity equated to exercise. That is, some men believed that sweating at work either through physical exertion or being outside in the heat at work counted as exercise $(n=20)$ :

- “Thank God that it's warm and at my job I sweat enough and burn off enough with what I'm doing. I think that's enough."

- 'I don't exercise, my work is like exercising, that's how I keep myself in check. I have an exercise machine and all that, but I don't use it."

- 'I still work, even though it's four hours a day. At work I travel around in a little buggy, but it involves a lot of getting up here and going over there and doing this and doing that, so I would call that pretty good exercise. At least I consider it exercise, otherwise I ain't doing it."

\section{Medication}

Many men were under the impression that adherence to medication was easier than lifestyle changes. Thus, for some men, medication adherence was the principal diabetes selfcare behavior. Taking medication was seen as involving no thinking, whereas, adherence to a healthy diet and exercise program required, in most cases, a drastic modification of habits (many culturally engrained) $(n=24)$ :

- 'I don't diet...I do take my medication because I'm supposed to."

- "I think that mostly it's the medicine, you should take it just like the doctor told you, and I do. I always follow the instructions. Uh, like my diet...yeah, like...the truth is that I don't. I try not to do it too often, but I have lost control a bit, but later I make up for it."

\section{Nonadherence profiles}

Focus group findings shed light on adherence profiles. For example, nonadherent men appeared to fit two nonadherence profiles: 1) intentional and 2) nonintentional (Table 3). In both instances portion control, lack of skills on healthy food choices, cultural beliefs and low self-efficacy emerged as significant influences on attainment and maintenance of diabetes self-care goals.

\section{Intentional nonadherence}

When men were intentionally nonadherent, they made no attempts at sticking to a prescribed treatment plan. Some made attempts in the past to adhere, but were unsuccessful, either because of a lack of skills on how to incorporate diet
Table 3 Hispanic men nonadherence profile

\begin{tabular}{ll}
\hline Intentional nonadherence & $\begin{array}{l}\text { Unintentional } \\
\text { nonadherence }\end{array}$ \\
\hline - No attempts are made to rectify & - Attempts are made to rectify \\
behavior & behavior \\
- Tired of taking medication & - Forgetful \\
- Feeling deprived & - Lack of skills \\
- Refuse to comply with diet & - Busy \\
recommendations & \\
\hline
\end{tabular}

recommendations into daily living or they experienced side effects of medication $(\mathrm{n}=11)$ :

- "There are times I have to take a pill and my sugar drops too low, so I start asking myself why am I taking this pill, it's gonna lower it too much."

Others were frustrated and angry about having "contracted" a disease that has rendered them powerless and vulnerable. They felt deprived of the foods they love and grew up eating, and refused to follow dietary recommendations $(n=15)$ :

- "I told my daughter, I have to die of something, let me at least die in peace."

These men were reluctant to invest the time and energy into changing life-long habits and customs that in their minds define who they are as men.

\section{Unintentional nonadherence}

Unintentional nonadherence occurred mainly as a result of having a hectic and busy lifestyles and lacking skills on how to cook and make healthy food choices. Nonetheless, these men made an effort to stick to recommendations and actively sought outside sources of information. Most knew when they strayed from guidelines, and attempted to rectify their behavior by resuming treatment plan. As with intentionally nonadherent men, unintentionally nonadherent men had experienced unpleasant medication side-effects. They attributed these experiences to instances where they did not follow recommendations. Unpleasant episodes represented a learning experience $(n=22)$ :

- "I had to take each of those incidents into account and say what can I do to change this?"

\section{Discussion}

This study was designed to provide insight into the belief systems and attitudes of male Hispanic patients with T2DM, and explore the reasons why Hispanic patients in a health care system have worse glycemic control than non-Hispanic whites or African Americans. We limited the present report to men only because there is little research focusing on adherence 
factors in Hispanic men with diabetes, and Hispanic men are the least likely group to report a usual source of care and frequent medical system contact. Thus, their attitudes and perceptions regarding diabetes management can be important in designing education and intervention programs.

This study revealed that Hispanic men have a generally fatalistic attitude about the long-term outcomes of their disease. They clearly understood that diet and physical activity were as important as taking medication. However, they expressed much stronger commitment to medication regimen adherence than to diet and physical activity. Participants expressed strong negative attitudes toward changing their traditional dietary patterns, and in combination with the sense of fatalism regarding the course of their disease, they seemed to have little motivation to attempt long-term dietary control. This lack of motivation often originated from the belief that Hispanic foods are inherently unhealthy, and therefore this meant that they couldn't have the foods they grew up eating, so why even bother. The misconception that Hispanic foods are unhealthy is consistent with a recent focus group analysis designed to inform the development of a culturally competent diabetes self-management program for Mexican Americans. ${ }^{23}$

Previous studies reported that Hispanics have difficulty following diet recommendations, because many do not know how to modify the traditional Mexican American dishes to conform to ADA guidelines ${ }^{23}$ or they perceive that a change in diet would require them to eat meals that are different from other family members. ${ }^{24,25}$ The high degree of nonadherence to dietary and physical activity recommendations in our study was also reported in an earlier cross-sectional survey conducted by Wen and colleagues. ${ }^{26}$ That study found that among older Mexican Americans, only one third of the sample reported following a healthful eating plan every day of the last seven days. Over $40 \%$ reported sporadic adherence to physical activity recommendations, and over one third reported not participating in any physical activity at all.

A handful of studies have reported on gender differences in diabetes self-management among Hispanics. Oomen and colleagues ${ }^{27}$ reported that Hispanic women may have difficulty adhering to diabetes management recommendations, because they view buying special foods, spending extra money for medication, and engaging in diabetes self-management routines as selfish behavior. For Hispanics, the family is an important source of support in coping with illness, but may also play a role in how successful the Hispanic patient will be in adhering to diabetes self-care recommendations. For example, Fisher and colleagues ${ }^{28}$ found that family structure and organization were associated with good diet and exercise adherence among nonelderly Hispanic patients with diabetes. However, Cherrington and colleagues ${ }^{29}$ described the family as being both a positive and negative influence on Hispanic patients' ability to manage their diabetes. For men family support for their illness was viewed as positive. In contrast, women often described a lack of support from family members.

Considerable emphasis has been placed on evaluating healthcare access barriers such as lack of insurance coverage, low income and education as major determinants of adherence. Our approach differed in that we explored potential barriers to diabetes management guidelines in a group of Hispanic men with equal access to care.

\section{Strengths/limitations}

The participants in this study were patients in a public health care system, and thus do not represent the entire spectrum of socioeconomic status of Hispanics in the US. In addition, the participants were mostly of Mexican or Central American origin, and the findings cannot be assumed to be generalizable to Hispanics of Puerto Rican or Cuban descent. Another potential limitation is the relatively small number of participants in the focus groups. Nonetheless, focus groups with fewer individuals allowed for more in-depth exploration of themes that emerged from the discussions. Luborsky and Rubinstein describe this process as "data adequacy," or collecting data until no new information is elicited. ${ }^{30} \mathrm{We}$ would like to emphasize that the purpose of the focus groups was not to report predictors of adherence to diabetes management recommendations, but rather it was used as a tool to enrich data not typically available in quantitative databases.

\section{Conclusion}

The loss of self-esteem and sense of fatalism that is engendered in Hispanic men who are diagnosed with type 2 diabetes should be an important consideration in planning counseling and education programs directed at this group. Rather than viewing strict adherence to the diabetes regimen as a way of maintaining full functional capacity, the men in our study viewed it as a way of avoiding symptoms and merely slowing down the rate of decline. Under this view, they valued the short-term gratification of indulging in their favorite food and drink more than any possible benefit from self-denial. Educational and counseling messages should stress that a diagnosis of diabetes is not a death sentence, and full functional capacity can be maintained with good control. 


\section{Acknowledgments}

This project was generously underwritten by Mrs Trinidad Mendenhall Sosa. We are also grateful to Dr Wendell Taylor for his guidance and support during data coding sessions, and Dr Abdul Syed for his assistance in moderating focus groups. The authors report no conflicts of interest in this work.

\section{References}

1. American Diabetes Association, Centers for Disease Control and Prevention. National Diabetes Fact Sheet: General Information and National Estimates on Diabetes in the United States, 2000. Atlanta, GA: US Department of Health and Human Services; 2000.

2. Centers for Disease Control and Prevention. National Diabetes Surveillance System. 2009. Accessed on Feb 19, 2009. Available from: http://www.cdc.gov/diabetes/statistics/index.htm.

3. Saydah S, Cowie C, Eberhardt MS, De Rekeneire N, Narayan KMV. Race and ethnic differences in glycemic control among adults with diagnosed diabetes in the United States. Ethn Dis. 2007;17:529-535.

4. American Diabetes Association. Standards of medical care in diabetes. Diabetes Care. 2004;27:S15-S35.

5. Vincent D, Pasvogel A, Barrera L. A feasibility study of a culturally tailored diabetes intervention for Mexican Americans. Biol Res Nurs. 2007;9:130-141.

6. Sobralske MC. Health care seeking among Mexican American men. J Transcult Nurs. 2006;17:129-138.

7. Brown ER, Ojeda VD, Wyn R, Levan R. Racial and ethnic disparities in access to health insurance. Los Angeles, CA: UCLA Center for Health Policy Research and The Henry J. Kaiser Family Foundation; 2000.

8. McCollum M, Hansen LB, Lu L, Sullivan PW. Gender differences in diabetes mellitus and effects on self-care activity. Gend Med. 2005;2:246-254.

9. Caban A, Walker EA. A systematic review of research on culturally relevant issues for Hispanics with diabetes. Diabetes Educ. 2006;32: 584-595.

10. Whittemore R. Culturally competent interventions for Hispanic adults with type 2 diabetes: A systematic review. J Transcult Nurs. 2007;18: 157-166.

11. Anders RL, Olson T, Wiebe J, Bean NH, DiGregorio R, Guillermina M, Ortiz M. Diabetes prevalence and treatment adherence in residents in a colonia located on the West Texas USA/Mexico border. Nurs Health Sci. 2008;10:195-202.

12. Nwasuruba C, Osuagwu C, Bae S, Singh KP, Egede LE. Racial differences in diabetes self-management and quality of care in Texas. J Diabetes Complications. 2009;23:112-118.
13. Nwasuruba C, Khan M, Egede LE. Racial/ethnic differences in multiple self-care behaviors in adults with diabetes. Soc Gen Intern Med. 2007;22:115-120.

14. Smith T. Mexican-Americans and diabetes: Factors influencing the prevalence of diabetes according to the PRECEDE Model. The Health Education Monograph Series. 1999;16:32-34.

15. Rosal MC, Olendzki B, Reed GW, Gumieniak O, Scavron J, Ockene I. Diabetes self-management among low-income Spanishspeaking patients: a pilot study. Ann Behav Med. 2005;29:225-235.

16. Vincent D, Clark L, Zimmer LM, Sanchez J. Using focus groups to develop a culturally competent diabetes self-management program for Mexican Americans. Diabetes Educ. 2006;32:89-97.

17. Krueger RA, Casey MA. Focus groups: A practical guide for applied research. Thousand Oaks, CA: Sage Publications; 2000.

18. Nvivo for Windows Version 7. Melbourne, Australia: QSR International; 2006.

19. Basch CE. Focus group interview: an underutilized research technique for improving theory and practice in health education. Health Educ $Q$. 1987; 14:404-411.

20. Bertrand JT, Brown JE, Ward VM. Techniques for analyzing focus group data. Eval Rev. 1992;16:198-209.

21. Pope C, Ziebland S, Mays N. Qualitative research in health care: Analyzing qualitative data. BMJ. 2000;320:114-116.

22. Mays N, Pope C. Qualitative research in health care: Assessing quality in qualitative research. BMJ. 2000;320:50-52.

23. Vincent D, Clark L, Marquez ZL, Sanchez J. Using focus groups to develop a culturally competent diabetes self-management program for Mexican Americans. Diabetes Educ. 2006;32:89-97.

24. Hunt LM, Pugh J, Valenzuela M. How patients adapt diabetes self-care recommendations in everyday life. J Fam Pract. 1998;46:207-215.

25. Anderson RM, Goddard CE, Garcia R, Guzman JR, Vazquez F. Using focus groups to identify diabetes care and education issues for Latinos with diabetes. Diabetes Educ. 1998;24:618-625.

26. Wen LK, Parchman ML, Shepherd MD. Family support and diet barriers among older Hispanic adults with type 2 diabetes. Fam Med. 2004;36:423-430.

27. Oomen JS, Owen JL, Suggs LS. Culture counts: why current models fail Hispanic women with type 2 diabetes. Diabetes Educ. 1999;25: 220-225.

28. Fisher L, Chesla C, Skaff MM, Gilliss C, Mullan JT, Bartz RJ, Kanter RA, Lutz CP. The family and disease management in Hispanic and European-American patients with type 2 diabetes. Diabetes Care. 2000;23:267-272.

29. Cherrington A, Ayala G, Sleath B, Corbie-Smith G. Examining knowledge, attitudes, and beliefs about depression among Latino adults with type 2 diabetes. Diabetes Educ. 2006;32:603-613.

30. Luborsky M, Rubenstein R. Sampling in qualitative research. Res Aging. 1995;17:89-113.
Patient Preference and Adherence

\section{Publish your work in this journal}

Patient Preference and Adherence is an international, peer-reviewed, open access journal that focusing on the growing importance of patient preference and adherence throughout the therapeutic continuum. Patient satisfaction, acceptability, quality of life, compliance, persistence and their role in developing new therapeutic modalities and compounds to

\section{Dovepress}

optimize clinical outcomes for existing disease states are major areas of interest. This journal has been accepted for indexing on PubMed Central. The manuscript management system is completely online and includes a very quick and fair peer-review system. Visit http://www.dovepress.com/ testimonials.php to read real quotes from published authors. 